Estudios Constitucionales, Año 16, No 1, 2018 pp. 365-394

ISSN 07180195

Centro de Estudios Constitucionales de Chile Universidad de Talca

"El derecho alternativo en el pluralismo jurídico ecuatoriano"

Eduardo Díaz Ocampo - Alcides Antúnez Sánchez

\title{
EL DERECHO ALTERNATIVO EN EL PLURALISMO JURÍDICO ECUATORIANO*
}

\author{
THE ALTERNATIVE RIGHT IN THE JURIDICAL ECUADORIAN PLURALISM
}

\author{
Eduardo Díaz OCAMPo ${ }^{1}$ \\ Universidad Técnica Estatal de Quevedo. Ecuador. \\ ediaz@uteq.edu.ec,edu66diaz@hotmail.com
}

Alcides Antúnez SÁnchez ${ }^{2}$ Universidad de Granma. Cuba. Contacto: aantunez@udg.co.cu,antunez63@nauta. cu,antunez1963@gmail.com

RESUMEN: El artículo examina al conflicto de competencia entre la jurisdicción ordinaria y la indígena, los procesos que se dan entre las dos jurisdicciones a partir del texto constitucional y el desarrollo normativo en el Ecuador. De este análisis queda claro que la jurisdicción ordinaria tiene competencia global sobre las conductas que se realizan dentro del territorio indigena y en consecuencia tienen facultad sancionatoria a partir del reconocimiento del cual se deriva el derecho de los miembros de las comunidades indígenas a un fuero y se concede el derecho de ser juzgado por sus propias autoridades, conforme a sus normas y procedimientos dentro de su ambiente territorial en pro de garantizar el respeto por la particular cosmovisión del individuo.

PALABRAS CLAVES: conflicto de competencia, constitución politica, derechos humanos, jurisdicción ordinaria, jurisdicción indígena.

ABSTRAC: The article examines the conflict of jurisdiction between ordinary jurisdiction and the native, the processes that take place between the two jurisdictions as from the constitutional text and the normative development in the Ecuador. It is clear of this analysis ordinary jurisdiction has global competition on the conducts that come true within the indigenous territory and in consequence they have punishing faculty as from recognition of whom derives the right of the members of the indigenous communities itself to a jurisdiction and it is conceded the right to be judged by his own authorities, in accordance with his standards and procedures within his territorial environment for the sake of guaranteeing the respect for the individual's particular worldvision.

KEYWORDS: conflict of jurisdiction, political constitution, human rights, ordinary jurisdiction, indigenous jurisdiction.

\footnotetext{
* Artículo recibido el 3 de marzo de 2017 y aprobado el 11 de abril de 2018.

1 Confróntese para profundizar Ayala Mora (2008), p. 19; Stavenhagen, (1980), pp. 303-316; Cabedo Mallol (1998), pp. 145-158; Constitución Política del Ecuador de 2008, Registro Oficial No 449 de fecha 20 de octubre 2008.

2 Constitución Política de la República de Ecuador de 1998, Registro Oficial No 1 de fecha 11 de agosto de 1998.
} 


\section{EXORDIO}

La historia devela que las sociedades indígenas, establecidas en el territorio que se reconoce como la República del Ecuador, como desde antes de la conquista española en América Latina existían ya costumbres ancestrales, las que no fueron respetadas por los invasores. Estas comunidades generaron prácticas sociales con el fin de regular las relaciones entre sus miembros y resolver los conflictos que pudieran presentarse, de lo que hoy se reconoce como Derecho indígena; por ello la Constitución de 2008, en su artículo 1º, define al Ecuador como: ... "un Estado constitucional de derechos y justicia, social, democrático, soberano, independiente, unitario, intercultural, plurinacional y laico..."; esta definición que hace la constituyente, define el cambio del paradigma constitucional vigente en el siglo XXI.

Si lo comparásemos con la Constitución de 1998, en la que se reconocía al país como: “...un Estado de derecho, soberano, unitario, independiente, democrático, pluricultural y multiétnico... ” Definición importante para la época, al demostrar los límites en la comprensión del pluralismo jurídico, pues se intentaba resolver el conflicto con una mirada antropológica, pero mantuvo criterios de exclusión y subordinación a los pueblos indígenas.

Los principios de plurinacionalidad e interculturalidad, reconocidos en la Carta Magna de 2008, se constata como se vincula con la noción del pluralismo jurídico, permitiendo reconocer la existencia de tantos sistemas jurídicos como nacionalidades existentes en el territorio ecuatoriano. El principio de igualdad y no discriminación consagrado en la Constitución, garantiza el goce de los derechos a todos los ciudadanos y extranjeros residentes en este país.

Esta Ley de leyes, en su artículo 57 regula: (...) "reconoce y garantizará a las comunas, comunidades, pueblos y nacionalidades indígenas, de conformidad con la Constitución y con los pactos, convenios, declaraciones y demás instrumentos internacionales de derechos humanos, los derechos colectivos (...)". Lo que demuestra, que además de permitirse la creación de circunscripciones territoriales cuando existan comunidades conformadas mayoritariamente por indígenas, impulsa la adopción de la administración especial luego de una consulta popular aprobada por al menos dos terceras partes de los votos, por razones de conservación, permite tener un régimen especial indígena, en el cual las autoridades territoriales tendrán competencia en virtud del principio de interculturalidad ${ }^{3}$.

3 Véase en este sentido Llasag Fernández (2009), pp. 179-210; Valarezo (2009), pp. 18-39. 
En la Constitución de la República de 2008, se toma en cuenta la facultad de las autoridades de las comunidades indígenas para juzgar, siempre aclarando que las decisiones de las referidas autoridades deberán tener concordancia con la propia Constitución y de los Convenios y Tratados Internacionales de Derechos Humanos, controlando la constitucionalidad de sus actos y decisiones por la Corte Constitucional; a la vez, se puede comprender algunos límites que pueden darse para el juzgamiento por parte de las autoridades indígenas, los mismos que serían establecidos mediante ley, principalmente las que tiene que ver con la circunscripción territorial, en donde se pone en juego los temas de la jurisdicción y su competencia, ante la ausencia de una norma que coordine ambas justicias ${ }^{4}$.

Entre los retos del Derecho en el siglo XXI, es la incorporación del denominado pluralismo jurídico o convergencia en un mismo espacio geográfico de dos o más sistemas jurídicos diversos o sencillamente la coexistencia e interacción de diferentes ordenamientos normativos. Las autoridades indígenas y los funcionarios judiciales como servidores públicos, la policía, los fiscales y autoridades de la función Ejecutiva, como los intendentes y los comisarios a nivel nacional, a más de los funcionarios de los gobiernos seccionales autónomos, han observado que los pueblos indígenas utilizan la interlegalidad, puesto que así lo consideran en su visión sociojurídica. El Derecho consuetudinario, revestido de sus características innatas, así como el derecho ordinario o estatal, permite demostrar que en algunas comunidades indígenas poseen reglamentos internos y se remiten al ordenamiento jurídico de las autoridades parroquiales, cantonales, provinciales o nacionales, dependiendo de la gravedad del caso.

La incorporación del manejo comunitario de los conflictos trae figuras como la mediación comunitaria o la conciliación comunitaria; un aspecto del Derecho indígena es el devolver la armonía quebrantada, recuperar las relaciones y si es posible la reconciliación; por lo que podemos constatar que no es una justicia eminentemente castigadora o exegética, pues se considera la situación tanto del agresor como de la víctima, así como de la costumbre. En tal virtud, la Ley Orgánica considerará la realidad sociológica, pues no existe un sistema jurídico indígena único, sino que hay muchos subsistemas que se adaptan a los diferentes

4 Wray Espinosa (1997), pp. 51-55. 
espacios y tiempos, de acuerdo con la realidad antropológica de cada pueblo o nacionalidad indígena, al operar con mismo dinamismo como cultura ancestral 5 .

Para la cosmovisión indígena el derecho a la vida es de toda la comunidad en colectividad, los indígenas valoran la vida en cuanto aporta a la comunidad, por ende, cuando uno de sus miembros es asesinado, los verdaderos afectados son los que se quedan llorando a sus seres queridos, por eso, busca resarcir el daño causado superando los conflictos internos para poder en conjunto devolver el equilibrio a su sociedad. En la justicia ordinaria, sin la intención de crear juicios de valor, se produce un acto de venganza en contra del acusado, intentando desaparecerlo para siempre de la sociedad al internarlo en la cárcel.

El artículo tiene como objetivo demostrar el conflicto de ley que pervive entre la justicia estatal en el ordenamiento jurídico ecuatoriano, en relación con la competencia de las autoridades indígenas para aplicar el Derecho indígena desde su cosmovisión social, histórica, económica y cultural como costumbre ancestral basada en el Derecho consuetudinario, se aportan elementos que podrán permitir la armonización en la solución del conflicto en su aplicación al cumplirse el mandato constitucional por la Asamblea constituyente. Para ello se utilizan los métodos de la investigación científica como el histórico lógico, el de inducción deducción y el de análisis y síntesis.

\section{EL ORDENAMIENTO JURÍDICO DEL ECUADOR Y EL Derecho indígena. Conflicto o armonía}

Como en todos los países que integran la región de América Latina, en Ecuador, la situación actual de los pueblos indígenas tiene sus antecedentes en las legislaciones coloniales y de la época ancestral. Tiene en común con los países andinos el hecho de que antes de la conquista española gran parte de lo que ahora es el territorio nacional estaba integrado en un régimen altamente estructurado sobre el cual ejercía su dominio el llamado imperio Inca ${ }^{6}$.

América Latina tiene 826 pueblos indígenas, con 45 millones de personas que representan el 8,3\% de la población total de la región, Ecuador con 1.018.176, representa el (7\%) en relación con los países, según datos de la Cepal en el 2010, y el censo realizado. Esta llegada de los españoles al territorio ecuatoriano, confrontó

5 Confróntense Olmedo Gavilanes, Raúl, Tesis de Máster: Derecho Consuetudinario Indígena: dicotomía en lo procesal y en la práctica, Universidad Católica de Santiago de Guayaquil, Ecuador (2015).

6 García, (2010), pp. 9-16. 
la conformación de distintos pueblos y nacionalidades indígenas originarios, los que nacieron y se desarrollaron en su propio territorio; estos tenían sus propias formas de organización social, actividad económica, ideología política, normas de conductas, de convivencia social, costumbres y culturas, con la finalidad de construir una gran nación, quienes tenían un acervo diverso de conocimientos en astronomía, técnicas agrícolas, medicina relacionada con las cualidades curativas de plantas y animales y un sistema de solución de conflictos. Se aprecia que muchas de estas características sociales han sobrevivido hasta nuestros días con las particularidades propias de cada comunidad con sus tradiciones ancestrales 7 .

Se reconoce, que dentro de la justicia indígena existe un antecedente que es fundamental para su participación que, en las épocas coloniales, donde se manejaba un sistema con un régimen con sanciones rigurosas, basado en costumbres ancestrales, y en la manera en que se administraba y aplicaba la justicia en las comunas ${ }^{8}$.

Por ello, los autores del ensayo analizan como en la Constitución ecuatoriana de 1998, se enfocaba la cuestión indígena al consagrar el pluralismo étnico, considerando que la República del Ecuador tiene entre 35\% - 40\% de población indígena agrupada en 14 nacionalidades y 18 grupos étnicos del total de la población nacional. Instituto Ecuatoriano de Estadísticas y Censos (INEC 2010)9 La región del Chimborazo registró el mayor porcentaje de población indígena en el Ecuador 38\% corresponden a la población indígena, seguido de las regiones Amazónicas, Morona Santiago, Pastaza y Napo. Una de las principales formas sociales que aún sobreviven dentro de las nacionalidades indígenas es la aplicación del Derecho consuetudinario. Existe una disposición constitucional desde 1998, sobre la creación de mecanismos que coordinen entre la jurisdicción ordinaria y la jurisdicción indígena, lo cual reviste de vital importancia, por cuanto, la aplicación de ciertos procedimientos propios de la justicia indígena es rechazado por un sector importante de la sociedad ecuatoriana que no pertenecen a sus comunidades, pueblos y nacionalidades, ratificada en el 2005, de las 14 nacionales y 18 etnias dentro de la nación ecuatoriana.

\footnotetext{
7 Ariza Santamaría (2015), p. 165-178.

8 Consúltese para profundizar Tiban Guala (2010), pp. 214-216; De Sousa Santos y Grijalva Jiménez (2012), pp. 13-67; Ilaquiche Licta (2015), p. 34; De Sousa Santos (2012), pp. 13-50.

9 Censo de Población realizado en el 2010, $1^{\text {ra }}$ edición, Quito, 2012, Disponible en: http://www. ecuadorencifras.gob.ec/resultados/
} 
Ante la falta de creación de los mecanismos de coordinación, los que consisten en la creación de cuerpos legales que regulen de manera general, los procedimientos, principalmente sancionatorios, que se aplican en el derecho indígena, hemos escogido ese tema como propuesta de intervención con la finalidad de presentar un proyecto de ley que establezca normas procedimentales de carácter general que se aplicarán en la justicia indígena. Ecuador, fue el primer país en incluir dentro de su marco jurídico a partir de su Constitución, se regulan y reconocen las disposiciones que facultan esta administración de justicia, al decir de Ayala Mora ${ }^{10}$. Los instrumentos internacionales de los derechos fundamentales del hombre, en los que se otorga el ejercicio de funciones jurisdiccionales a las autoridades de las comunidades, pueblos y nacionalidades indígenas, basados en sus costumbres y tradiciones han sido reconocidos por el Ecuador. Garantizándose por el Estado ecuatoriano, el respeto de las instituciones y autoridades a las decisiones de la jurisdicción indígena, siempre que las mismas se establezcan en armonía con los principios y normas constitucionales.

En la práctica, esta realidad ha generado una serie de conflictos conceptuales y formales tanto de los diversos operadores judiciales como en la ciudadanía en general, pues, por una parte, han aceptado dentro del Derecho positivo el concepto, han sido muy escasos los pronunciamientos judiciales legales y constitucionales al respecto y en el otro ámbito, se evidencia un desconocimiento o descoordinación en la teoría y la práctica, entre algunos líderes indígenas y miembros de las comunidades.

Lo que permite demostrar que los resultados de los estudios realizados desde la década de los 70 del pasado siglo XX, en el contexto de las políticas integracionistas desde la ciencia del Derecho, dentro de las constituciones de América Latina y el Caribe se empezó a reconocer la existencia de algunos derechos específicos a las Comunidades indígenas, ejemplo e ilustración de lo señalado son los hechos acontecidos en el caso de la violación de los derechos indígenas en Ecuador, en la comunidad Kichwa de Sarayaku, promovidos ante la Comisión Interamericana de Derechos Humanos en 1990, por la vulneración del medio ambiente por contaminación por vertido; en el Cantón Guamote en la provincia de Chimborazo, por vulnerarse las garantías constitucionales y afectar física y sicológicamente a las personas en el período 2009-2012, al extralimitarse en sus funciones, propiciando castigos físicos y sicológicos inhumanos y ajusticiando sin observar los mínimos

10 Ayala Mora (2002), p. 91. 
jurídicos como el juicio previo y el debido proceso e irrespetando las normas establecidas por la Constitución de la República y los Tratados Internacionales ratificados por el Ecuador a fin de garantizar la plena vigencia de los derechos humanos; el caso de la comunidad La Cocha en el 2010, en la comunidad Kichwa, ante la intromisión violenta de las autoridades estatales, la persecución a las autoridades indígenas y la transgresión de los operadores de Justicia Estatales, al no permitir el debido proceso en contraposición al texto constitucional, en respaldo al reclamo de los derechos indígenas ante el doble juzgamiento ${ }^{11}$.

Sin embargo, como todavía primaba la identidad Estado-Derecho no se reconoció formalmente a las Autoridades indígenas, con la facultad de aplicar su propio sistema normativo de un modo amplio en el Derecho indígena, tal y como lo refieren en sus posturas Ávila Santamaría, Serrano Cajamarca y Hermosa Mantilla ${ }^{12}$. En algunos países, se constata como se decretó el ejercicio del propio sistema normativo de modo amplio, solo para casos de poca importancia o gravedad y entre indígenas, a finales del siglo; en la década de los 90' del siglo $\mathrm{XX}$, los países andinos reconocen que buscan garantizar la pluralidad cultural y el derecho a la identidad cultural, como es el caso del Ecuador ${ }^{13}$.

También se constata como se les reconoció a los pueblos indígenas sus derechos, su idioma oficial, se les protegió sus costumbres, sus trajes típicos, y se les promovió su cultura ancestral. Estos elementos analizados permiten a los autores considerar el comportamiento que ha tenido la justicia indígena en el contexto del Ecuador a partir del pluralismo jurídico, de su reconocimiento en la constitución y en el desarrollo dentro del ordenamiento jurídico en esta nación de la región de América Latina, de sus zonas de conflicto y de cómo será posible su armonización.

A partir de definir qué es el Derecho indígena, los autores analizan que ¡el reconocimiento de los derechos indigenas de los pueblos indigenas es el resultado de la lucha y los levantamientos en diferentes politicas del Ecuador, cuáles? para ello es necesario mencionar que las diversas formas de luchas dadas a lo largo de la historia colonial y republicana, son respuestas a las condiciones de postergación de los pueblos y de esta manera catalogarlo así con la articulación de los grandes levantamientos que buscaban instituir en el país modificaciones estructurales e

11 Consúltese para profundizar Llasag Fernández (2007); Tiban Guala, (2013); Fiallo Monedero (2014); Serrano Cajamarca (2015); Corte Constitucional de la República del Ecuador, http//:www.cc.ec en Sentencia No 026-12-SIS-CC, la Sentencia No 007-09-SEP, la Sentencia No 077-12-SEP, y la Sentencia No 065-12-SEP.

12 Hermosa Mantilla (2014), pp. 151-182.

13 Véase en este sentido Ávila Santamaría (2011), pp. 101-261; Garzón López, (2012). 
históricas como visibilizar al movimiento indígena en el Estado y la sociedad el reconocimiento institucional de la diversidad de identidades, su cosmovisión, su dignidad, sus derechos, costumbres, tradiciones, idioma y el reconocimiento del Pluralismo Jurídico y la administración de la Justicia indígena.

Los pueblos y nacionalidades indígenas desde sus orígenes han desarrollado su propio Derecho y son aquellos que pertenecen a los pobladores originados u originarios de un territorio que ha sido invadido y colonizado por forasteros, por quienes se constata que los pueblo indígenas han sufrido injusticias históricas por haber sido despojados de sus territorios, tierras y recursos, de la misma manera tenemos que tener en cuenta que el Derecho se encuentra escrito y su relación con los pueblos indígenas, no es una idea clara. El Estado ha impuesto un sistema jurídico único, rígido, inflexible como de ejemplo que constate la afirmación; sin considerar la heterogeneidad de culturas que tienen los diversos pueblos que componen el territorio nacional ${ }^{14}$.

Estudiosos del Derecho indígena ecuatoriano, como Llasag Fernández y Hermosa Mantilla, reconocen que en la historia de la legislación ecuatoriana se evidencia también las políticas de exclusión y aislamiento del Derecho Indígena, lo mismo que en la cultura y la economía del país. Toda vez que la estructura institucional se manifiesta desde una imposición vertical, desde un Estado uninacional, al no conseguirse aún la armonización adecuada en este reconocido pluralismo jurídico ${ }^{15}$.

En ese contexto, es conveniente reseñar algunas definiciones que ubican el papel del Derecho indígena y su protagonismo en el desarrollo de la soberanía, aun no tiene una contextualización adecuada, que permita su adecuada armonización. Entre ellos La confederación de nacionalidades indígenas del Ecuador (CONAI), aporta la definición de que se considera Derecho Indígena, permite: "Para nosotros los indios, el Derecho Indígena es un derecho vivo, dinámico, no escrito, el cual a través de un conjunto de normas regula los más diversos aspectos y conductas del convivir comunitarios" 16 .

Pérez Guartambel considera que el Derecho Indígena es el conjunto de preceptos, instituciones y procedimientos ancestrales, sustentadas en la cosmovisión filosófica presentes en la memoria colectiva, dinamizados y reconocidos por la

14 Noguera Fernández (2008), pp. 133-158

15 Consúltese Llasag Fernández (2014), pp. 295-319; Cfr. Hermosa Mantilla, pp. 151-182.

16 Véase Wolkmer (2006), p. 194; Yrigoyen Fajardo (2004), pp. 1-25. 
comunidad cuya prevención y aplicación corresponde a sus autoridades, tutoras del natural equilibrio social ${ }^{17}$.

Las posturas de los autores estudiados para la elaboración de este ensayo consideran, coinciden que el Derecho Indígena es el conjunto de normas legales, no escritas, ni codificadas, estas son distintas del ordenamiento jurídico de un país determinado, este derecho es adecuado para mantener un comportamiento y una buena convivencia social y pacífica con todos los miembros de un territorio determinado. Cabe entonces reconocer a partir de que es un Derecho consuetudinario, que no se encuentra escrito, es de carácter y tradicional, su trasmisión oral corresponde más a un código moral de justicia y está basado en las costumbres y tradiciones de cada pueblo, comunidad o nación indígena. La aceptación y el respeto de las reglas de estos derechos consuetudinarios en sustentos objetivos de poder y autoridad, pero también en mecanismos subjetivos de solidaridad, cooperación y reciprocidad.

Se corrobora que la costumbre jurídica tiene un carácter normativo, exigido por una necesidad psicológica y social, real o imaginaria de la colectividad. El Derecho indígena tiene esta naturaleza, esta costumbre es reconocida aceptada y compartida por la comunidad. Esta costumbre por la situación jurídica, social, cultural, geográfica, y regional de los pueblos indígenas es de gran diversidad y eso implica que sus normas y tradiciones difieran de un lugar a otro en su aplicación y reconocimiento como rasgo distintivo que lo caracteriza. Los principios de la existencia del Derecho Indígena se aprecian a partir de su origen por dos instituciones diferentes tanto en el tiempo como en el espacio, pero con el pasar de los tiempos han transformado en la razón del ser del Derecho indígena dentro del marco legal que se constituye hoy en la actualidad como pueblos y nacionalidades indígenas. A pesar de los cambios sufridos en la institucionalidad y las normas de los pueblos indígenas, debido a la transformación social y las relaciones de producción perduran y están en vigencia sus instituciones sociales, económicas, políticas y jurídicas, basadas en principios, normas y valores.

Los autores del ensayo valoran que, a partir de la concepción que ha tenido el Derecho indígena, se puede determinar que los cambios constantes de los pueblos indígenas se basan en los principios de solidaridad, reciprocidad, colectividad, son los sustentos fundamentales en la elaboración de la normativa, del ordenamiento social y del surgimiento del Derecho Indígena en América Latina, reconocidos en

17 Pérez Guartambel (2015), pp. 177-179. 
el Ecuador. Para ello, son identificadas para una mejor comprensión las características que posee este Derecho Indígena, al decir de Pérez Guartambel, estas son:

\begin{tabular}{|l|l|}
\hline Características & \multicolumn{1}{c|}{ Contenido } \\
\hline Comunidad & $\begin{array}{l}\text { Es autoridad, unidad, organización, solidaridad, es vida o supervivencia. } \\
\text { Es una colectividad conformada por personas descendientes de indígenas } \\
\text { originarios que habitaron en el vasto territorio de la ANBY AYALA antes de } \\
\text { la conquista y colonización ibérica. }\end{array}$ \\
\hline Autoridad & $\begin{array}{l}\text { Colectivos indígenas, provistos de pensamiento, saberes, pasiones, emocio- } \\
\text { nes, sentimientos, unidos en una comunidad por lazos de consanguinidad, } \\
\text { vínculos sociales, culturales, filosóficas, articulados socialmente por una } \\
\text { autoridad dentro de una institución unipersonal y pluripersonal en cada } \\
\text { pueblo con facultades expresas y reconocidas por la propia comunidad. }\end{array}$ \\
\hline Legislación & $\begin{array}{l}\text { El Derecho Indígena cuenta con preceptos que ya dejamos señalados ante- } \\
\text { riormente y son aplicados a todos por igual, sin privilegios, discrimen y peor } \\
\text { resentimiento, algunas conductas han sido modificadas en función de las } \\
\text { demandas sociales concertadas por la comunidad indígena. }\end{array}$ \\
\hline Procedimientos & $\begin{array}{l}\text { Inicia con la denuncia, luego la investigación, la resolución, el correctivo y } \\
\text { no concluye sino holísticamente, continua con el seguimiento. }\end{array}$ \\
\hline
\end{tabular}

¿Qué reconocer entonces por Justicia Indigena? La norma jurídica que vela el interés de la colectividad para que de esta manera sus miembros vivan en armonía en conformidad a las costumbres normas y reglas que existan dentro de la circunscripción territorial indígena, se denota que a partir de estos acontecimientos importantes nacen significativos aportes sobre todo en las relación jurídica del indígena en el país, hasta entonces la administración de la justicia que se practicaba en las comunidades a lo largo de la historia era completamente problematizada y se encerraba en la antijuricidad para la legislación ordinaria y no como parte de la identidad cultural del pueblo ecuatoriano.

Lo que permite analizar que la Constitución de la República del Ecuador de 2008, en su artículo 171, señala: es la norma suprema que reconoce la jurisdicción indígena y determina que:

..." Las autoridades de las comunidades, pueblos y nacionalidades indígenas ejercerán funciones jurisdiccionales, con base en sus tradiciones ancestrales y su propio derecho, dentro de su ámbito territorial, con garantía de participación y decisión de las mujeres. Las autoridades aplicarán normas y procedimientos propios para la solución de sus conflictos internos, y que no sean contrarios a la Constitución y a los derechos humanos reconocidos en instrumentos internacionales. El Estado garantizara que las decisiones de la jurisdicción indigena sean respetadas por las instituciones y autoridades. Dichas decisiones estarán sujetas al control de constitucionalidad. La Ley establecerá los mecanismos de coordinación y cooperación entre la jurisdicción indígena y la jurisdicción ordinaria....". 
Entonces, la juricidad de la justicia indígena, no solo es porque la Constitución del Estado le reconozca desde hace una década atrás, pues fue ratificada en el año 2008, sino porque los pueblos y nacionalidades indígenas aún sin el reconocimiento constitucional han venido regulando la conducta social colectiva a través de sus propios sistemas legales o del Derecho propio en sus comunidades. A manera de ejemplificar e ilustrar lo señalado, ¿es legal y aplicable la justicia indigena?, lo que no es antijurídico y lo que no es aplicable y debe ser castigado o sancionado por la justicia ordinaria es el linchamiento, la justicia por mano propia y los ajustes de cuentas. Es por ello, luego de este interrogante, que se valora que la justicia indígena deberá a futuro tener un control constitucional ${ }^{18}$.

Por consiguiente, los autores se afilian a lo señalado en sus estudios realizados por Ferrajoli, Fix Zamudio, Zafaroni, Villavella Armengol, por la relación con el tema a partir de lo reconocido en el Derecho consuetudinario y lo introducido en la normativa interna en los países que se reconoce el Derecho Indígena, en especial en cuanto a lo relacionado con la técnica de introducir las políticas ambientales a partir del texto constitucional, desarrollado en los ordenamientos jurídicos internos de las naciones del contexto latinoamericano, que permiten ponderar el binomio deber-derecho a través de la Ley Federal de Responsabilidad Ambiental (2014), una Ley General del Cambio Climático (2015), una Ley de Derechos de la Madre Tierra en Bolivia (2015) y una Ley de Tribunales Ambientales en Chile (2015) y los derechos otorgados a la naturaleza a través del texto constitucional en Ecuador y Bolivia como referentes. Considerados como los cuerpos jurídicos probados en los ordenamientos jurídicos de la región Andina, se pueden tomar en cuenta en otras regiones del planeta Tierra, para con ello lograr el principio del desarrollo sostenible como paradigma de las Administraciones Públicas por sus servidores públicos. Siendo la novedad haber declarado sujeto a la naturaleza, en los textos constitucionales de Bolivia y Ecuador, aunque estén en construcción y desarrollo, han modificado la tendencia del Derecho occidental, donde en su matriz está el pensamiento de los pueblos originarios en preservar y proteger la naturaleza (Pachamama) ${ }^{19}$.

¿Podrá ser aplicada la justicia indigena en forma total y sin restricciones de acuerdo con la teoría de pluralismo emancipador? Esta interrogante nos lleva a diversas lecturas, que parten del nivel comprensivo y educativo de las comunidades

18 Chávez Vallejo (2016).

19 Profundícese Ferrajoli (2010); Zaffaroni (2011), pp. 103-117; Villabella Armengol (2010), pp. 51-76. 
indígenas, se busca una mejoría en la justicia indígena, por ser vista como una necesidad, pero que para ello se necesita del seguimiento de las comunidades que practican este tipo de actos, ya que en las mismas debe existir capacitación para que se haga un buen uso del poder por parte de las autoridades comunitarias, con el debido conocimiento de las leyes a aplicar. Toda acción que realicen los comuneros debe ser conocida por la justicia indígena. Al igual que se solicita un Código de justicia indígena para este tipo de encuentros donde se involucra a la comunidad para hacer justicia por sus derechos, con respeto hacia su cultura ancestral. Es necesario que exista esta clase de castigos de forma moderada, para no causar daño hacia la dignidad de las personas involucradas, al igual que hacia los niños que presencian esta clase de eventos. Y que posterior a esto sean llevados hacia las autoridades o que las mismas sean realizadas con presencia de las estas, por ser este castigo una práctica tradicional de sanación de ortiga y azotes para mejorar el equilibrio social, debido a que las leyes no cumplen con una sanción correcta hacia los infractores de las mismas.

Por ello, se constata la coyuntura de la democracia participativa a partir del nuevo constitucionalismo en América Latina, reflejado en los textos constitucionales de Ecuador, Venezuela y Bolivia, los que han tratado la cuestión ambientalista con mayor rigor dentro de su desarrollo normativo interno, los cuales han sido parte del conflicto de la justicia indígena, como es el caso de la comunidad Kichwa de Sarayaku, el que fue promovido ante la Comisión Interamericana de Derechos Humanos en 1990, por la vulneración del medio ambiente ante la contaminación por vertido ocasionada por una petrolera extranjera en su nación. A partir de que las culturas deben ser reconocidas por su pluriculturalidad en el sector ecológico y en el participativo, que tributen a mejorar el desarrollo y el bienestar de los ciudadanos con una adecuada calidad de vida, y no como sigue ocurriendo por las transnacionales que laboran en la nación en la explotación de recursos naturales, las que incluso generan derecho.

Prosiguiendo en este iter, la justicia indígena a partir de los estudios realizados por Salgado Pesantes, Ariza Santamaría ${ }^{20}$, entre otros, en el Estado plurinacional del Ecuador, a partir de los postulados constitucionales, refieren:

20 Véase Salgado Pesantes, Hernán, "La nueva dogmática constitucional en el Ecuador", en Revista jurídica UNAM, Disponible en: hptt//: www.juridicas.unam.mx (Consultada en fecha 30 de julio 2017) pp. 9811002; Cfr. Ariza Santamaría, pp. 165-178. 
"...El Ecuador como un Estado intercultural y plurinacional, su reconocimiento se encuentra establecido en la Constitución Política del Ecuador del año 2008, donde las nacionalidades y los pueblos indigenas son reconocidos sus derechos colectivos en lo que se refiere al ámbito juridico y particularmente en el establecimiento del pluralismo jurídico, la misma que conlleva al reconocimiento de los valores, principios y normas jurídicas, y este contexto constitucional marca el inicio del nuevos estado plurinacional de nuestros derechos individuales y colectivos, de esta forma revitaliza las prácticas de usos y costumbres..."21.

En este plano, se considera que el Ecuador por ser un país plurinacional, es un logro constitucional que va marcando un hito en la lucha por los derechos colectivos como sujetos de derechos, en tal virtud, la Constitución de 2008, reconoce derechos específicos en un plano de igualdad. Por lo que no hay culturas inferiores ni superiores, los colectivos indígenas gozan de autonomía interna para resolver sus problemas internos en base a sus tradiciones y costumbres propias, ello es un mandato constitucional ${ }^{22}$.

Ello es validado a partir de que el texto constitucional de 2008, en su artículo 171, reconoce la jurisdicción indígena y en consecuencia refiere:

"...las autoridades de las comunidades, pueblos y nacionalidades indígenas ejercerán funciones jurisdiccionales, con base en sus tradiciones ancestrales y su propio derecho, dentro de su ámbito territorial, con garantía de participación y decisión de las mujeres. Las autoridades aplicarán normas y procedimientos propios para la solución de sus conflictos internos, y que no sean contrarios a la Constitución y a los derechos humanos reconocidos en instrumentos internacionales. El Estado garantizará que las decisiones de la jurisdicción indigena sean respetadas por las instituciones y autoridades. Decisiones que estarán sujetas al control público de constitucionalidad en sede judicial realizado por parte de los servidores públicos. Para ello la Ley establecerá los mecanismos de coordinación y cooperación entre la jurisdicción indigena y la jurisdicción ordinaria como principios a tenerse en cuenta por las partes..." 23 .

Con este reconocimiento en el texto Magno de 2008, las nacionalidades o pueblos indígenas poseen el derecho a conservar y desarrollar sus formas propias de organización social, con ello se valora que el sistema jurídico es el conjunto de instituciones, normas, principios y valores que rigen la conducta o comporta-

\footnotetext{
21 Constitución Política de la República del Ecuador, Registro Oficial No 449, 20 de octubre 2008. Artículo 1.

22 Confróntese Yrigoyen Fajardo (2003), pp. 1-18; Yrigoyen Fajardo, Disponible en: http://6ccr.pgr.mpf. gov.br/destaques-do-site/3_RYF_2010. (Consultada en fecha 21 de enero 2017).

23 Consúltese Bustamante (2011), p. 19; Zabala Egas (2010), p. 277.
} 
miento de los miembros de la comunidad entre sí, con todos y cada uno de ellos dentro de las comunidades y que sirven para resolver los conflictos que amenazan la supervivencia de la comunidad o de la seguridad de sus miembros. El Estado plurinacional es una solución virtuosa de esa articulación histórica de vida, de idiomas, de culturas, etc., no es un tema de debate meramente intelectual, aunque sí tiene su vertiente teórica, es un hecho práctico de una realidad en construcción en Ecuador. En sí se aprecia que es un bloque de poder construido a partir del ensamble de varias matrices culturales, lingüísticas e históricas.

Por ello, se aprecia que, en el desarrollo de la normativa interna, en el Código Orgánico de la Función Judicial (2008), en su artículo 171 dispone: "la actuación de los jueces, fiscales y defensores y otros servidores judiciales, y demás servidores públicos deben observar en los procesos los principios administrativos. Los autores del ensayo, valoran como se aplica la justicia indígena, la que para su configuración deben concurrir varios elementos viables, comprobables a partir de la jurisdicción y competencia como: el territorio indígena, la presencia de autoridad indígena, el debido proceso, la defensa de las partes, y la aplicación de normas y procedimientos propios. Las autoridades indígenas que dirigen la aplicación de la justicia indígena en los pueblos y nacionalidades indígenas son producto de un proceso de evolución dentro de su estructura interna. Muchas denominaciones tradicionales han cambiado de connotación y denominación a partir de la promulgación de la Ley de Organización y Régimen de las Comunas (2012) y la Ley Orgánica de Instituciones Públicas Indígenas (2014) en el desarrollo normativo a partir de los derechos reconocidos por la carta magna (2008) en el Ecuador, como parte del desarrollo normativo en el ordenamiento jurídico, pero aún los autores del ensayo valoran que no es suficiente, pues pervive el conflicto.

$\mathrm{Al}$ ser este un Derecho consuetudinario como se ha citado, y que como derecho dinámico está sometido a cambios estructurales en el tiempo, los sistemas culturales tienen contacto tan estrecho con otras culturas diferentes a diferencia de la cultura anterior que se encontraba aisladamente, por ello la supervivencia de los usos y costumbres es muy poco usada en la actualidad. Se distingue en la aplicación del Derecho Indígena, el derecho al "debido proceso", esto constituye un límite a la jurisdicción especial indígena, lo que implica el cumplimiento de reglas acorde con la especificidad de la organización social, política y jurídica de la comunidad que se trate. faltan instrumentos internacionales de derechos humanos que los protegen.

Este límite según la Conaie (2006) no exige que las prácticas y procedimientos deban ser llevados a cabo de la misma manera que como lo hacían los antepa- 
sados, porque el derecho de las comunidades indígenas, como cualquier sistema jurídico, puede ser dinámico. Lo que se requiere es el cumplimiento de aquellas actuaciones que el acusado puede prever y que se acerquen a las prácticas tradicionales que sirven de sustento a la cohesión social. Se analiza, como las autoridades indígenas se conforman de acuerdo con la Ley de Organización y Régimen de las comunas, estas no mantienen las mismas denominaciones culturales en cada una. Las actuaciones de las autoridades indígenas son justas y legítimas porque se basan en sus costumbres para la aplicación de la justicia indígena y mantienen el respeto al derecho del debido proceso que garantiza el ejercicio pleno de los derechos fundamentales de los individuos, tal y como se refirió en el desarrollo del epígrafe 24 .

Se aprecia, como en la mayoría de los pueblos y de las nacionalidades indígenas, aparte de tener un Cabildo como la máxima autoridad legal, también se respeta a las autoridades denominadas culturalmente como son los padrinos/padres de familia y los abuelos o curacas de la comunidad. Otro rasgo que distingue a las autoridades indígenas en el sistema de justicia indígena es que no existe la distribución de la competencia en razón al grado, territorio, personas y materia como tal; pero al analizar las actuaciones de las respectivas autoridades indígenas en relación con la justicia ordinaria, estas se encajan dentro de los diferentes tipos de competencia reconocidos y aplicados por la justicia ordinaria, como territorio, materia y persona. Todo este análisis permitirá adentrarnos en el conflicto de leyes entre el Derecho Indígena y el ordenamiento jurídico del Ecuador, a tenor de los casos ya reseñados en este epígrafe.

\section{El conflicto de leyes entre el Derecho indígena Y EL ORDENAMIENTO JURÍDICO ECUATORIANO}

Ante la interrogante de ¿por qué surge el conflicto de leyes y cuáles son sus causales? a partir de lo señalado por Espinosa y Caicedo, quienes sentaron pautas, al reseñar que el pluralismo jurídico constituye una de los conceptos centrales tanto de la Antropología como de la Sociología jurídica, y se refiere a la coexistencia de sistemas jurídicos diversos dentro de un mismo campo social ${ }^{25}$.

${ }^{24}$ Para profundizar véase Atienza (2004), p. 128; Yrigoyen Fajardo (2006), pp. 537-567; Bonilla y ArizA (2007), pp. 24-34.

25 López López (2014), pp. 31-64; Bustillos Ramírez (2014), pp. 33-49. 
Para Pérez Arroyo, el pluralismo jurídico significa la coexistencia de varios sistemas normativos, al margen de su reconocimiento legal o no del Estado nacional, lo que si es necesario es su existencia como sistema jurídico de un pueblo, que lo reconoce como válido y efectivo, dentro del Estado o del espacio geopolítico determinado. Considera el pluralismo intrasistémico (desde dentro y hacia adentro del sistema cultural), que contiene los casos, como se ha visto, de disidencia y objeción de conciencia que un individuo plantea a su propio Estado en razón de su libertad ideológica, de religión o de conciencia, y, el extrasistémico (desde fuera y hacia afuera del sistema cultural), este condicionamiento cultural se origina y motiva en el seno de una cultura distinta, foránea respecto del marco de referencia cultural normativa. Esto ocurre también en las sociedades de pasado colonial, originando que las leyes y normas de conducta de la cultura dominante terminan por imponerse a modo de cultura oficial, desplazando a las otras culturas nativas en razón a su estatus de culturas subyugadas y criminalizando muchas veces, los usos y costumbres.

En este plano, se valora que la existencia del pluralismo jurídico permite que los pueblos y nacionalidades indígenas puedan aplicar sus principios y normas consuetudinarias para poder resolver los conflictos, sin tener que someterse al sistema dominante, al cual durante años han sido subordinados los pueblos indígenas. Con el pluralismo jurídico se rompe el monismo jurídico, los pueblos indígenas tienen la oportunidad de acudir a los sistemas jurídicos que ellos crean pertinente, sabemos que los pueblos indígenas pueden elegir el sistema estatal o el sistema indígena para la solución de sus conflictos, claro está que siempre se deberá observar la competencia que tenga la autoridad para conocer el caso, dentro de esto también es importante aclarar que se debe evitar que el infractor sea juzgado dos veces por una misma causa, pues de lo contrario se afectaría uno de los principios internacionales conocido como non bis in idem ${ }^{26}$.

El pluralismo jurídico permite romper las imposiciones jurídicas, y posibilita la convivencia de varios sistemas jurídicos, que serán aplicados de acuerdo con sus principios y costumbres aceptados y reconocidos por los pueblos y nacionalidades indígenas. El pluralismo impulsa la construcción de un Estado democrático en la cual se permita la participación de todos los ciudadanos de manera democrática, para que así pueda existir en un Estado pluralista, como es el caso de Ecuador. Pero para lograr la verdadera armonización, se considera que se deberá llegar a

26 Consúltese para profundizar Pazmiño Freire (2015); Ron Erráez (2011); Llerena GarCÉs, (2015). 
entendimientos para desarrollar un vínculo de comunicación para que el sistema sea claro y tolerante, que tribute a mejorar los derechos y oportunidades de los indígenas, y que exista un respeto por su pluriculturalidad. El Pluralismo jurídico parte de la necesidad de una interpretación pluricultural de las leyes, es decir, del reconocimiento de diferentes funciones, contextos y fines sociales de las distintas normas jurídicas. En este sentido, el pluralismo jurídico refleja una aplicación de la pluriculturalidad oficial que antes mencionamos, añade un sistema basado en el reconocimiento e inclusión indígena a la estructura legal, sin hacer mayor transformación a ella en término del otro sistema no indígena. El propósito es de dar atención y cabida a la particularidad étnica, no a repensar la totalidad. Como así lo vienen señalando los estudios sobre el tema por Trujillo 27.

Hay también detractores de esta teoría, al señalar que la existencia de varios sistemas jurídicos podría generar conflictos internos, pues desde la creación del Estado nación, únicamente el Estado por medio de su poder legislativo puede crear normas para imponer deberes, establecer ciertos bienes jurídicos y derechos subjetivos correspondientes. Así los vínculos jurídicos suponen deberes y derechos, que provienen de normas jurídicas y, como éstas de manifestaciones de voluntad del órgano que las produce. La existencia del pluralismo jurídico, se dice que afectaría a la soberanía del Estado, quien tendría que limitarse en sus ocasiones y no podrían subsumir bajo el señorío a todos los ciudadanos, pero esta afirmación es errada, pues el Estado mantiene su soberanía para velar por el bien de todos los ciudadanos y no debemos olvidar que los pueblos y nacionalidades indígenas también son ciudadanos.

¿Cómo se resuelve entonces el conflicto de leyes?, los autores parten comenzando por entender que jurisdicción no es más que "el poder que tienen las autoridades para gobernar o administrar en un espacio territorial determinado, es la potestad o facultad que tienen los jueces, magistrados y autoridades para administrar justicia, es decir para conocer, juzgar y sancionar las infracciones o delitos". También puede señalarse que la jurisdicción indígena se refiere a la potestad de los pueblos indígenas de recurrir a sus autoridades e instancias internas para dar solución a las controversias que se generen dentro de sus territorios, así como a la facultad de tomar decisiones, juzgar y ejecutar hechos de acuerdo con sus normas tradicionales ${ }^{28}$.

27 Véase para profundizar Trujillo (2008), p. 268; Trujillo, Grijalva y Endara (2001), pp. 33-35.

28 Consúltese para profundizar Montaña Pinto y Pazmiño Freire (2013), pp. 38-47; Luzuriaga Muñoz (2017); Alarcón Peña (2009), pp. 668-671. 
Al analizar el Código de Procedimiento Civil Ecuatoriano (2013), en su artículo $1^{\circ}$, se determina: "La jurisdicción es el poder de administrar la justicia, consiste en la potestad pública de juzgar y hacer ejecutar lo juzgado en una materia determinada, potestad que corresponde a los magistrados y jueces establecidos por las leyes". "Esta norma jurídica dispone que el poder de administrar justicia nace por dos vias: por la jurisdicción legal y por convención y acuerdo...".

La jurisdicción indígena no nace de la ley, esta nace de la voluntad o convicción de los miembros del pueblo o de la colectividad, es la propia gente que acude donde la persona o personas consideradas como autoridades o líderes, para pedir que se arregle un conflicto o problema. Por lo tanto, el derecho también es integral que busca restaurar el desequilibrio causado por el problema, conflicto o llaki. Sus autoridades buscan resolver el problema de manera integral, su principal interés es restablecer la vida comunitaria y devolver la armonía. Las autoridades indígenas que ejercen la administración de justicia obedecen a un procedimiento existente desde tiempos atrás. Respetando las particularidades de cada uno de los pueblos indígenas, se puede mencionar en forma general cuáles son los pasos o los procedimientos que las autoridades indígenas utilizan para solucionar un conflicto interno. Esta se origina a partir del primer paso que deben dar los afectados es poner en conocimiento de los dirigentes del Cabildo de manera oral y clara todo lo acontecido, trátese de peleas, chismes, robos, muerte, etc.

En este sentido, señalaremos como en la lengua indígena se aborda la materia procesal en la aplicación del Derecho indígena, no así en la emisión de cuerpos jurídicos por el Derecho estatal, lo cual constituye parte del conflicto; el willachina es un acto por el cual el ofendido formula la petición de solución al Cabildo, petición que posteriormente será el tema principal de resolución en la asamblea. La víctima o cualquier persona, de manera oral, expone el tema ante las autoridades indígenas. La etapa que le continúa se denomina tapuykuna, es para la investigación del problema con una variedad de diligencias como la inspección ocular o constatación del hecho en el caso de muertes, robos, peleas; propensos a identificar la magnitud del conflicto. Procede como continuidad, la chimbapurana, para la aclaración de los hechos ante la asamblea de la comunidad. En esta etapa se identifican a los responsables del hecho y se dicta la resolución, la misma que consta en actas. El acusado tiene derecho a la legítima defensa. La killpichirina, es la etapa donde se impone las sanciones dependiendo de la gravedad de los hechos, como las multas, la devolución de los objetos robados más las indemnizaciones, el baño de agua fría, ortiga, fuete o látigo, trabajos comunales excepcionalmente se aplica la expulsión de la comunidad, éstas basados en los reglamentos internos 
de la comunidad. La ejecución de la sanción, denominada paktachina, es donde las corporales como el látigo, el agua, y la ortiga son ejecutados por hombres, mujeres de buena reputación y honestidad, ellos son: los padres, los padrinos, los abuelos y las autoridades indígenas, como el presidente y su directiva de la comunidad los ancianos, los sabios, entre otros, elegidos y reconocidos por la asamblea de la comunidad ${ }^{29}$.

Se demuestra que la justicia indígena se adapta a los diferentes lugares y tiempos, de acuerdo con los modos de vida y a la realidad de cada pueblo o nacionalidad aborigen, a diferencia de la norma jurídica; los autores aprecian como se reconoce y preserva el idioma indígena como cultura ancestral, reconocida en el texto constitucional, pero no desarrollado en cuerpos jurídicos de manera adecuada. El artículo 10, de la Constitución de la República del Ecuador de 2008, señala: "Las personas, comunidades, pueblos, nacionalidades y colectivos son titulares y gozarán de los derechos garantizados en la Constitución y en los instrumentos internacionales..."30.

Las normas que rigen el debido proceso en la toma de decisiones de las autoridades indígenas, tienen su soporte legal a partir de la Constitución de la República de 2008, esta le otorga al Derecho Indígena fuerza jurídica dentro del Estado y a la vez le impone los límites que no debe sobrepasar, unos límites también delineados por el contexto legal internacional, especialmente el relativo a los derechos humanos y concretamente por el Convenio 169 de la Organización Internacional del Trabajo sobre Pueblos Indígenas y Tribales en países independientes de 1989, ratificado el 15 de mayo de 1998 por Ecuador ${ }^{31}$.

El texto legal de 2008, regula en el artículo 191 que: "las autoridades de los pueblos indígenas ejercerán funciones de justicia, aplicando normas y procedimientos propios para la solución de conflictos internos de conformidad con sus costumbres o derecho consuetudinario, siempre que no sean contrarios a la Constitución y las leyes..." reconociendo las prácticas repetidas en forma sistemática que a fuerza de la repetición la colectividad (pueblos, nacionalidades y comunidades indígenas), no solo las acepta como válidas, sino que las considera obligatorias por su necesaria garantía de orden social. En esta misma línea, se constata como en el artículo 171, reconoce como legítimas a las autoridades que las comunidades indígenas

\footnotetext{
29 Para profundizar consúltese Cfr. Tiban Guala, pp. 214-216; Sánchez Botero (2000), p. 137; Llasag FERnÁNDEZ (2006), pp. 749-760.

30 Constitución Política de la República del Ecuador, Registro Oficial o 449, de 20 de octubre 2008.

31 Cfr. Wray Espinosa, pp. 51-55.
} 
designan de acuerdo con las normas de derecho propio o consuetudinario, se tratan de mandatos de dar, hacer o no hacer algo, que provienen de una autoridad facultada para expedirla para los miembros de la comunidad y que son exigibles a terceros a través de la autoridad encargada de velar por su cumplimiento, aun con el empleo de la violencia legítima ${ }^{32}$.

Es decir, son cuerpos jurídicos que se originan de una autoridad indígena competente, donde se concentran los tres poderes que existen en la justicia ordinaria, reconocida como legítima depositaria de esta facultad, sin que exista peligro de que se vulneren derechos ya que todo se decide en asamblea general donde todos sus miembros participan. La administración de justicia indígena no es homogénea pues cada comunidad tiene sus normas particulares para sancionar un acto de una manera distinta, por lo que intentar codificar el sistema de administración de justicia indígena en un código no es lo más adecuado, a más de que iría contra la constitución y los instrumentos internacionales que reconocen este derecho colectivo eminentemente consuetudinario. Para las comunidades indígenas todas sus sanciones tienen una finalidad fundamental que no va con el simple castigo, sino que la finalidad principal es regenerar al individuo y reinsertarlo en la comunidad, a más de las medidas preparatorias que se den a favor del afectado y con esto retomar la armonía en la comunidad.

¿Dónde se aprecia la diferencia entre la jurisdicción ordinaria y la jurisdicción indígena? Se diferencian porque al momento de juzgar se aplican penas distintas, la primera de acuerdo con la ley, y la segunda de conformidad con las normas y costumbres; sin embargo, el fin es el mismo, mantener el orden jurídico, la paz y la armonía en la sociedad. Por lo que le corresponderá resolver el conflicto de leyes a partir de lo que se reconoce en la Constitución de la República del Ecuador de 2008, norma jurídica que establece el principio del "debido proceso", la aplicación de la justicia indígena estará a cargo de las autoridades de las comunidades indígenas; este tipo de sanción es más rápida y en muchos casos los moradores manifiestan que es más efectiva, pero se vulnera por la justicia ordinaria, como es el caso La Cocha ocurrido la comunidad Kichwa, ante la intromisión violenta de las autoridades estatales, la persecución a las autoridades indígenas y la trans-

32 Consúltese para profundizar Flores Cartagena (2015). 
gresión de los operadores de Justicia Estatales, al no permitir el debido proceso en contraposición al texto constitucional ${ }^{33}$.

Empero, los conflictos que derivan de la coexistencia del ordenamiento jurídico positivo y el sistema de justicia indígena que deben ser resueltos por el ente competente y los sectores involucrados con el fin de garantizar el acceso a la justicia en el marco del respeto a los derechos humanos tanto individuales como colectivos de los individuos en este Ecuador intercultural y plurinacional.

En efecto, uno de los rasgos centrales que dimensiona jurídicamente a América Latina, radica en su pluralidad normativa y cultural; elemento que posibilita la práctica del pluralismo jurídico, o sea, la convivencia de normas que reclaman obediencia en un mismo territorio y que pertenecen a sistemas distintos. En la Amazonía, las nacionalidades indígenas acuden al sistema ordinario cuando enfrentan un problema considerado poco frecuente dentro de la comunidad o desconocido por las prácticas ancestrales, también acuden a la justicia ordinaria cuando se ha perdido la costumbre aplicable o cuando existen amenazas por una de las partes involucradas hacia la otra, como en los casos de asesinatos o violación. En caso de problemas que involucren a indígenas, como conflictos relacionados con el territorio, el medio ambiente, y los recursos naturales, las nacionalidades indígenas acuden a la justicia ordinaria por falta de reglas claras que faciliten la intervención de las autoridades indígenas.

Este ensayo permite demostrar que el Estado ecuatoriano vive un pluralismo jurídico que necesita ser sistematizado, esto se lograría con la implementación de una norma que regule y aclare los conflictos de competencia y jurisdicción de la justicia indígena respecto de la justicia ordinaria, que otorgue los lineamientos a seguirse para no caer en la violación de los derechos fundamentales tanto individuales y colectivos de los individuos; la Constitución en la parte final del artículo 171, establece "La ley establecerá los mecanismos de coordinación y cooperación entre la jurisdicción ordinaria..”. Esto hasta la fecha no se ha hecho y por esta situación se sigue teniendo inconvenientes al momento de ejercer justicia que desencadena en la violación de los derechos del individuo o en la impunidad de un acto delictivo, por lo que es menester que se adopten los mecanismos pertinentes que subsanen estos conflictos jurisdiccionales como resultado de que el Ecuador es

33 Confróntese para profundizar Cevallos MaZa (2009); Vintimilla (2009), p. 19; Flores (2011), pp. 1-17; Pérez Guartambel (2015), pp. 1-9. 
un país con una amplia diversidad social, cultural, étnica que lo definen como un estado pluralista en todo sentido ${ }^{34}$.

Sirva entonces para continuar estudiándose y profundizándose en la temática en futuras investigaciones desde una dimensión teórica, lógica y práctica, que permita la adecuada argumentación jurídica en la solución de los conflictos del Derecho indígena dentro del ordenamiento jurídico ecuatoriano, como han sido los casos analizados en este estudio para su futura armonización, toda vez que el pluralismo jurídico sigue siendo un paradigma en la nación ecuatoriana en construcción y desarrollo y queda pendiente por la Constituyente regular la Ley de deslinde entre ambas justicias desde el 2008, han transcurrido nueve años y no se cumple este mandato constitucional 35 .

Estos elementos trascienden de la aplicación de la justicia, es ponderado por los autores del ensayo jurídico que debe pensarse en un proceso de reingeniería en la Corte Constitucional, a través de jueces profesionales e indígenas, un ejemplo es el Tribunal Plurinacional constituido en la nación de Bolivia, la que también está entre las naciones que han reconocido al pluralismo jurídico en su texto Magno.

\section{A MANERA DE CONCLUSIONES}

Los pueblos indígenas tienen derechos al igual que todas las personas, derechos reconocidos no solo por la Constitución Política del Ecuador de 2008, sino también por los Tratados internacionales. Así, conforme a sus necesidades, aparece desde tiempos de antaño la aplicación de la justicia indígena basada en la costumbre y en la tradición de cada una de las comunidades a las cuales pertenece a partir del Derecho consuetudinario.

La legislación ecuatoriana a partir de la Constitución de 1998, en su artículo 191, y la Constitución de 2008, en su artículo 171, reconocen otros sistemas jurídicos dentro del Estado, aplicados por las colectividades indígenas. Estas comunidades tienen derecho a establecer libremente su condición jurisdiccional, eligen a sus representantes para que tengan jurisdicción y competencia, sus decisiones son respetadas por el sistema judicial ordinario como Pluralismo jurídico.

En la Constitución de la República del Ecuador de 2008, se establecen disposiciones expresas sobre el principio del debido proceso y la aplicación de la

34 Véase Díaz Ocampo (2015), pp. 1-10; Díaz Ocampo y Antúnez Sánchez, (2016), pp. 1-38.

35 Consúltese para profundizar Romano (1951), pp. 13-27; De LuCAS (1992); BobBio (1995), p. 164; Alexy (1997); Aguiló Regla (2000), pp. 11-28; Atienza (2009), p. 29. 
justicia indígena, a cargo de las Autoridades que forman parte de las comunidades indígenas, este tipo de sanciones es más rápida y efectiva que la justicia ordinaria.

La Constitución del Estado ecuatoriano, de 2008, garantiza que las decisiones de las autoridades que conforman la jurisdicción indígena sean respetadas por las Autoridades de la justicia ordinaria, las resoluciones emitidas tienen que ser dadas de acuerdo con su cosmovisión indígena, sus normas, sus creencias y costumbres respecto a la Constitución, los Tratados y Convenios Internacionales de Derechos Humanos ratificados por el Estado ecuatoriano.

El Derecho Indígena pervive en las costumbres de los pueblos y nacionalidades indígenas desde la ancestralidad. Las Autoridades de las comunidades indígenas basan sus resoluciones en el diálogo con el infractor, sometiéndolo a la vergüenza pública en caso de incumplimiento de la norma, y la posterior reinserción del sujeto a la sociedad una vez cumplida su pena para así mantener la paz social, con armonía y equilibrio en su territorio. Contribuye al sistema judicial dictando resoluciones de acuerdo a las normas y costumbres de las comunidades indígenas, ayuda a distribuir los casos de acuerdo a la jurisdicción y competencia disminuyendo la carga procesal para el Estado.

La Justicia Indígena es uno de los temas con mayor intervención y preocupación en la Administración comunitaria y de la Administración estatal, como principio de desarrollo tiene costumbres, tradiciones y prácticas propias: de comunidad, autoridad, legitimidad, legalidad, correctiva, pública, gratuita, igualitaria, preventiva, participativa etc., además de ser la base de la libre determinación de los pueblos y nacionalidades indígenas del Ecuador. La jurisdicción ordinaria y la jurisdicción indígena se diferencian porque al momento de juzgar se aplican penas distintas, la primera de acuerdo con la ley, y la segunda de conformidad con las normas y costumbres; sin embargo, el fin es el mismo, mantener el orden jurídico, la paz y la armonía en la sociedad.

El reconocimiento de los derechos colectivos de los pueblos indígenas y sobre todo la concepción del Estado como una sociedad diversa, heterogénea, pluricultural y multiétnica, permite afirmar la existencia del pluralismo jurídico en el Ecuador, dentro del concepto coexistencial de dos o más sistemas jurídicos dentro de un mismo territorio. La interculturalidad que define la Constitución de 2008 admite el diálogo entre los pueblos y nacionalidades indígenas con otros pueblos y la nación ecuatoriana blanca y mestiza, permitiendo la integración y la convivencia entre iguales, respetando la diversidad cultural; de la misma manera el principio de plurinacionalidad que nos garantiza el pleno ejercicio de los derechos y garantías de todas las nacionalidades existentes en el país. 
Las autoridades indígenas que aplican la justicia indígena son reconocidas tanto por la jurisdicción indígena como por la jurisdicción ordinaria, ejecutan sus resoluciones según sus costumbres, espiritualidad, tradiciones, procedimientos, prácticas, normas y creencias, desde su cosmovisión y organizando a sus autoridades conforme a su norma, favoreciendo la integración y la convivencia entre culturas. La facultad de la autoridad indígena está reconocida y garantizada en la Constitución de la República de 2008, no la limita debido a cuantía o gravedad del delito, se refiere exclusivamente, a que las autoridades de la justicia indígena tendrán jurisdicción y competencia cuando se trate de conflictos en las comunidades indígenas.

En concordancia con la Constitución de la República de 2008, el fallo pronunciado por parte de las Autoridades Indígenas tiene fuerza de cosa juzgada y debe cumplirse cabalmente; cuando una autoridad de la justicia ordinaria decide que se debe poner a consideración de la justicia ordinaria, ésta no está respetando sus derechos colectivos y consuetudinarios, tal como se reconoce en el desarrollo normativo de Ecuador.

Para la cosmovisión indígena el derecho a la vida es de toda la comunidad en colectividad, los indígenas valoran la vida en cuanto aporta a la comunidad, por ende, cuando uno de sus miembros es asesinado, los verdaderos afectados son los que se quedan llorando a sus seres queridos, por eso, busca resarcir el daño causado superando los conflictos internos para poder en conjunto devolver el equilibrio a su sociedad. En la justicia ordinaria, sin la intención de crear juicios de valor, se produce un acto de venganza en contra del acusado, intentando desaparecerlo para siempre de la sociedad al internarlo en la cárcel.

\section{BibLIOGRAFÍA CONSUlTADA}

AA. VV. (2012): El pluralismo jurídico en Ecuador desde la visión de los pueblos y nacionalidades indígenas. Viviendo la justicia. Pluralismo jurídico y justicia indigena en Ecuador (Quito, Editorial Manthra) pp. 36-39.

AA. VV. (2012): Viviendo la justicia. Pluralismo jurídico y justicia indígena en el Ecuador (Quito, Editorial Manthra) pp. 33-51.

AA. VV. (2012): Pluralismos 11 tesis, Centro de Estudios Constitucionales (España, Universidad Católica Boliviana San Pablo, Universidad de Barcelona) pp. 11-329.

AA. VV. (2011): Los derechos individuales y derechos colectivos en la construcción del pluralismo jurídico en América Latina (Bolivia, Editorial Garza Azul) p. 21. 
Aguiló, Josep (2008): Sobre Derecho y argumentación (Palma, Editorial Lleonard Muntaner) pp. 11-28.

Ávila Santamaría, Ramiro (2008): "Ecuador. Estado constitucional de derechos y justicia. Constitución del 2008 en el contexto andino”. Análisis de la doctrina y el Derecho Comparado, en Serie Justicia y Sociedad, (No 3), pp. 19-38.

Ayala Mora, Enrique (2002): El Derecho Ecuatoriano y el aporte indigena, Justicia Indigena. Aportes para un debate (Quito, Editorial Abya- Yala), p. 91.

Ayala Mora, Enrique (2008): Resumen de historia del Ecuador (Quito, Editorial Corporación Nacional), $3^{a}$ edición actualizada, p. 19.

Ariza Santamaría, Rosembert (2015): "El pluralismo jurídico en América Latina y la nueva fase del colonialismo jurídico en los Estados constitucionales", en Revista Insurgencia, (No 1), pp. 165-178.

Ariza Higuera, Libardo y Bonilla Maldonado, Daniel (2007): El pluralismo jurídico. Contribuciones, debilidades y retos de un concepto polémico (Colombia, Editorial Siglo del Hombre), p. 22.

AleXY, Robert (1997): Teoría de la Argumentación Jurídica, traducción de Manuel Atienza (Madrid, Centro de Estudios Constitucionales), p. 208.

Alarcón Peña, Pablo (2009): Protección de los derechos sociales en la jurisprudencia constitucional ecuatoriana, en la protección judicial de los derechos sociales (Quito, Ministerio de Justicia y Derechos Humanos), pp. 668-671.

Andrade De Ubidia, Santiago (2002): Justicia Indigena, aportes para un debate, (Quito, Editorial Abya Yala), pp. 137-156.

Aseff, Lucía María (2014): Teorías críticas del Derecho. Pluralismo jurídico (Argentina, Universidad Nacional de Rosario), p. 7 y ss.

Atienza, Manuel (2004): El pluralismo jurídico, Diccionario jurídico. Filosofía y Teoría del Derecho e información jurídica (Granda, Editorial Comares), p. 128.

Bobbio, Norberto (1995): Teoría de Ordenamiento Jurídico (Brasil, Editorial Universidade de Brasilia) G edición, p. 164.

Bustamante, Colón (2011): Nueva Justicia Constitucional neoconstitucionalismo derechos y garantías. Teoría y Práctica (Quito, Editorial Jurídica del Ecuador), p. 19.

Bustillos Ramírez, Linda (2014): "Algunos elementos para la configuración de los Estados plurinacionales en América Latina desde los derechos indigenas", en RJUAM, (No 29), pp. 33-49. 
Cabedo Mallol, Vicente (1998): "Derecho Consuetudinario y Jurisdicción Indígena. El pluralismo jurídico en Colombia, Perú, Bolivia y Ecuador", en Cuadernos Constitucionales de la Cátedra Fadrique Furio Ceriol (No 25), pp. 145-158.

Calderón Astete, Rodrigo (2013): Tesis Doctoral: Pensar otro Derecho. Para una nueva poiética jurídica (España, Universidad Pablo De Olavide).

Cóndor Chuquiruna, Eddie (2011): Los Derechos Individuales y Derechos Colectivos en la Construcción del Pluralismo Jurídico en América Latina (Bolivia, Comisión Andina de Juristas Bolivia), pp. 16 y ss.

ChÁvez Vallejo, Gina (2016): Tesis Doctoral: El control constitucional de la Justicia Indígena en el Estado Plurinacional: el caso ecuatoriano (España, Universidad de Valencia).

De Sousa Santos, Boaventura (2012): Justicia Indígena. Plurinacionalidad e interculturalidad en Ecuador (Quito, Editorial Abya-Yala).

De LuCAS, Javier (1992) Introducción a la Teoría del Derecho (Valencia, Editorial Tirant lo Blanch).

Díaz Ocampo, Eduardo (2015): "La formación en la justicia indígena como alternativa frente al pluralismo jurídico”, en Revista Didasc@lia: Didáctica y Educación, (No 3) pp. 1-10.

Díaz Ocampo, Eduardo y Antúnez Sánchez, Alcides (2016): "La Justicia indígena y el pluralismo jurídico en el Ecuador. El constitucionalismo en América Latina”, en Revista Derecho y Cambio Social, pp. 1-38.

Ferrajoli, Luigi (2000): "Garantías”, en Revista Jueces para la Democracia, (No 38), pp. 73-92.

Fix-Zamudio, Héctor (2010): "Los derechos humanos y su protección jurídica en Latinoamérica”, en Revista Ciencias Jurídicas UNAM.

Fiallo Monedero, Liliam (2014): Tesis de Maestría: ¿Monedas de oro para los Chanchos? Pluralismo jurídico en Ecuador. El caso de la nacionalidad Tsachila (Ecuador, Facultad Latinoamericana de Ciencias Sociales).

Flores, Daniela (2011): La Justicia Indígena y sus Conflictos con el Derecho Ordinario, (Quito, Equipo Jurídico INREDH) pp. 1-17.

Flores CarTagena, Raúl (2015): Tesis de Máster: Criterios jurisprudenciales para una adecuada aplicación del principio de interculturalidad al vulnerar el artículo 171, de la Constitución de la República, (Ecuador, Flacso).

GARCÍA, Fernando (2010): "Retos de la diversidad: el reconocimiento y aplicación de los sistemas de derecho indígenas ecuatorianos", en Revista de Ciencias Sociales (No 38) pp. 9-16. 
Garzón López, Pedro (2012): Tesis Doctoral: Multiculturalismo, ciudadanía y derechos indígenas: hacia una concepción decolonial de la ciudadanía indígena (España, Universidad Carlos III de Madrid).

Gregor Barié, Cletus (2008): "Derecho Indígena y Medios Alternativos de Resolución de Conflictos", en Revista Urvio (No 3), pp. 110-118.

Hans-Jürgen, Brandt; Franco Valdivia, Rocío (2006): El tratamiento de conflictos: Un estudio de Actas en 133 comunidades indigenas y campesinas en Ecuador y Perú, Lima: Forma e Imagen, Serie Justicia Comunitaria en Los Andes: Perú y Ecuador, Volumen 1, (Perú, Instituto de Defensa Legal) pp. 1-219.

Hermosa Mantilla, Hernán (2014): De los derechos colectivos de los pueblos indígenas al neo constitucionalismo Andino (Quito, Editorial Adya-Yala).

ILAQUiCHe LICTA, Raúl (1999): Tesis Doctoral: La Costumbre como fuente principal del Derecho Indigena, (Quito, Universidad Central del Ecuador).

ILAQUiCHE LICTA, Raúl (2015): Derecho propio, pluralismo jurídico y la administración de justicia indígena en el Ecuador (Quito, Editorial Jurídica del Ecuador) p. 34.

ILAQUICHE, Raúl (1999): Tesis doctoral: La Costumbre como fuente principal del Derecho Indígena (Universidad Central del Ecuador).

Ilaquiche Licta, Raúl (2015): Derecho Propio, Pluralismo Jurídico y la Administración de Justicia Indígena en el Ecuador (Ambato, Editorial Uniandes) pp. 121-122.

Jiménez LuQue, Toni (2013): Tesis de Maestría: Una mirada a los pluralismos jurídicos en América Latina desde un enfoque de interculturalidad y pluralismos jurídicos críticos, (Universidad Católica Boliviana San Pablo).

Kelsen, Hans (1992): Compendio de Teoría General del Estado, (México, Editorial Colofón) $1^{\text {ra }}$ edición, p. 140.

LÓPEZ LÓPEZ, Liliana (2014): "El pluralismo jurídico: una propuesta paradigmática para repensar el Derecho", en Revista Umbral (No 4) pp. 31-64.

Luzuriaga Muñoz, Enrique (2017): Tesis de Maestría: Problemática jurídica en torno a la competencia en la justicia indígena: caso Saraguro (Ecuador, Universidad Andina Simón Bolívar).

LLASAG FERNÁNDEZ, Raúl (2007): Tesis de Maestría: Jurisdicción indígena especialy su respeto en la jurisdicción estatal (Ecuador, Universidad Andina Simón Bolívar).

Llasag Fernández, Raúl (2009): La jurisdicción indígena en el contexto de los principios de plurinacionalidad e interculturalidad. La nueva constitución de 
Ecuador. Estado, derechos e instituciones (Quito, Universidad Andina Simón Bolívar) pp. 179-210.

LLASAG Fernandez, Raúl (2006): "Jurisdicción y competencia en el Derecho Indígena o consuetudinario", Anuario de Derecho Constitucional Latinoamericano, tomo 2, México, pp. 749-760.

Llano, Jairo Vladimir (2012): “Teoría del Derecho y pluralismo jurídico", en Revista Criterio Jurídico, pp. 191-214.

Llerena Garcés, Guillermo (2015): Tesis de Maestría: Aplicación de la acción extraordinaria de protección de las decisiones indigenas frente la justicia indigena y el pluralismo jurídico (Universidad de Ambato, Uniandes).

Melgarito Rocha, Alma Guadalupe (2015): Pluralismo jurídico: realidad oculta. Análisis crítico-semiológicos de la relación Estado-pueblos indígenas (México, Centro de Investigaciones Interdisciplinarias en Ciencias y Humanidades) pp. 3-9.

MiRIAS, Núria (2009): Tesis Doctoral: Lenguaje, praxis, razón. El problema del pluralismo a través de la filosofía del lenguaje, (España, Universidad de Barcelona).

Montaña Pinto, Juan y Pazmiño Freire, Patricio (2013): Algunas consideraciones acerca del nuevo modelo constitucional ecuatoriano. Manual de justicia constitucional ecuatoriana (Quito, Corte Constitucional del Ecuador) pp. 38-47.

Olmedo Gavilanes, Raúl (2015): Tesis de Maestría: Derecho Consuetudinario Indígena: dicotomía en lo procesal y en la práctica, (Universidad Católica de Santiago de Guayaquil).

PaCARI, Nina (2002): Justicia Indigena. Aportes para un debate (Quito, Editorial Abya Yala) pp. 83-90.

Pazmiño Freire, Leoncio Patricio (2015): Tesis Doctoral: La acción extraordinaria de protección en Ecuador: cuestiones de legitimidad y eficacia, (España, Universidad de Valencia).

Pérez GuartambeL, Carlos (2015): Justicia Indígena, (Ecuador, Editorial Talleres Gráficos de la Universidad de Cuenca) pp. 177-179.

Pérez Guartambel, Carlos (2015): La Justicia Indigena amenazada de muerte en el Ecuador, (Quito, Ecuarunari) pp. 1-9.

Rocha, Alma Guadalupe (2015): Pluralismo jurídico: realidad oculta. Análisis crítico-semiológicos de la relación Estado-pueblos indígenas, (México, Centro de Investigaciones Interdisciplinarias en Ciencias y Humanidades) p. 74.

Romano, Santi (1951): L'ordenamento guiridico, (Firenze, Editoriale Sansoni) pp. 13-27. 
Ron Erráez, Patricia (2011): Tesis de Máster: El control constitucional de las decisiones jurisdiccionales indígenas en Ecuador (Universidad Andina Simón Bolívar).

Rosillo Martínez, Alejandro (2008): Derechos Humanos pensamiento crítico y pluralismo jurídico, (México, Editorial Comisión Estatal de Derechos Humanos de San Luis de Potosí) $1^{\text {ra }}$ edición, p. 211.

San Martin Solano, Dayani (2013): Tesis de Máster: Justicia indígena y derechos humanos en el Austro ecuatoriano a partir del 2008 (Universidad de Cuenca).

SÁNCHez Botero, Esther (2000): La jurisdicción especial indígena, (Quito, Editorial s/n) p. 137.

Salgado Pesantes, Hernán (2017): "La nueva dogmática constitucional en el Ecuador”, en Revista jurídica UNAM, Disponible en: hptt//: www.juridicas. unam.mx (Consultada en fecha 30 de julio 2017) pp. 981-1002.

Serrano Cajamarca, Daniel (2015): Tesis de Máster: La "última ratio" del derecho constitucional ecuatoriano a la resistencia, (Ecuador, Universidad Andina).

Stavenhagen, Rodolfo (1980): Introducción al Derecho indígena (Academia Mexicana de Derechos Humanos) pp. 303-316.

TAmariz OchOA, María (2010): Tesis de Maestría: Logros de las comunidades, pueblos y nacionalidades indigenas en el ámbito de la interculturalidad en el Ecuador (Universidad de Cuenca).

Tiban Guala, Lourdes (2013): Tesis de Máster: Neoconstitucionalismo y Pluralismo, (Ambato, Uniandes).

Tiban Guala, Lourdes (2010): Estado Intercultural, Plurinacional y Derechos Colectivos en el Ecuador, (Quito, Fundación Hanns Seidel) pp. 214-216.

Trujillo, Julio César (2008): Justicia indígena y pluralismo jurídico. Derechos, costumbres y jurisdicciones indígenas en la América Latina contemporánea (Madrid, Editorial Laura Giraudo) p. 268.

Trujillo, Julio César; Grijalva, Agustín y Endara, Ximena (2001): Justicia Indígena en el Ecuador (Quito, Universidad Andina Simón Bolívar) pp. 33-35.

Valarezo, Galo (2009): ¿Plurinacionalidad o interculturalidad en la Constitución?, Plurinacionalidad, democracia en la diversidad (Quito, Editorial Abya-Yala) pp. 18-39.

Vintimilla, Jaime (2009) "Administración de Justicia Indígena en el Ecuador", en Revista Novedades Jurídicas, p. 19.

Villabella Armengol, Carlos Manuel (2014): Nuevo constitucionalismo latinoamericano, ¿un nuevo paradigma?, (México, Editorial Grupo Mariel). 
Villabella Armengol, Carlos Manuel (2010): El Derecho Constitucional del siglo $X X I$ : un cambio de paradigma. Estudios sobre el nuevo constitucionalismo latinoamericano, (Valencia, Editorial Tirant lo Blanch) pp. 51-76.

Walsh, Catherine (2008): Interculturalidad y Plurinacionalidad: Elementos para el debate constituyente, (Universidad Andina Simón Bolívar).

Wray Espinosa, Alberto (1997): El Convenio 169 de la OIT sobre los derechos de los pueblos indígenas y el régimen constitucional ecuatoriano, (Quito, Editorial Adya-Yala) pp. 51-55.

Wolkmer, Antonio Carlos (2007): Pluralismo jurídico: nuevo marco emancipatorio en América Latina, Pluralismo Jurídico. Teoría y experiencias, (México, Editorial Facultad de Derecho de la Universidad Autónoma de San Luís Potosí) p. 17.

Yrigoyen Fajardo, Raquel (1999): Pautas para la coordinación entre el Derecho indigena y el Derecho estatal (Guatemala, Editorial Fundación Myrna Mack) $1^{\text {ra }}$ edición, p. 13.

Yrigoyen Fajardo, Raquel (2003): Pluralismo jurídico, Derecho indígena y jurisdicción especial en los paises Andinos (Colombia, Perú, Bolivia, Ecuador (Colombia, Editorial ISLA) pp. 1-18.

YRIgOYen FajARDO, Raquel (2010): "El pluralismo jurídico en la historia constitucional latinoamericana: de la sujeción a la descolonización”. Disponible en: http://6ccr.pgr.mpf.gov.br/destaques-do-site/3_RYF_2010. (Consultada en fecha 21 de enero 2017).

YRIGOYEN FAJARDO, Raquel (2008): Hitos del Reconocimiento del pluralismo jurídico y el Derecho indígena en las políticas indigenistas y el constitucionalismo andino. Pueblos Indígenas y derechos humanos (Bilbao, Universidad de Deusto) p. 538.

Yrigoyen Fajardo, Raquel (1995): Un Nuevo Marco para la Vigencia y Desarrollo Democrático de la Pluralidad Cultural y Jurídica. Constitución, Jurisdicción Indígena y Derecho Consuetudinario, Desfaciendo Entuertos (Lima, Editorial CEAS) p. 5.

ZaFfaroni, Raúl (2011): La naturaleza con derechos. De la filosofía a la política (Quito, Editorial Abya-Yala) pp. 103-117.

Zabala Egas, Jorge (2010): Derecho Constitucional, neoconstitucionalismo y argumentación jurídica, (Guayaquil, Editorial Edilex) p. 277. 